Article

\title{
Deformations Prior to the Brumadinho Dam Collapse Revealed by Sentinel-1 InSAR Data Using SBAS and PSI Techniques
}

\author{
Fábio F. Gama ${ }^{1, *(D)}$, José C. Mura ${ }^{1}$, Waldir R. Paradella ${ }^{1}$ and Cleber G. de Oliveira ${ }^{2}$ \\ 1 National Institute for Space Research (INPE), São José dos Campos, 12227-010 São Paulo, Brazil; \\ jose.mura@inpe.br (J.C.M.); waldir.paradella@inpe.br (W.R.P.) \\ 2 VISIONA Tecnologia Espacial, São José dos Campos, 12247-016 São Paulo, Brazil; \\ cleber.oliveira@visionaespacial.com.br \\ * Correspondence: fabio.furlan@inpe.br; Tel.: +55-12-32086517
}

Received: 17 August 2020; Accepted: 18 September 2020; Published: 9 November 2020

\begin{abstract}
Differential Interferometric SAR (DInSAR) has been used to monitor surface deformations in open pit mines and tailings dams. In this paper, ground deformations have been detected on the area of tailings Dam-I at the Córrego do Feijão Mine (Brumadinho, Brazil) before its catastrophic failure occurred on 25 January 2019. Two techniques optimized for different scattering models, SBAS (Small BAseline Subset) and PSI (Persistent Scatterer Interferometry), were used to perform the analysis based on 26 Sentinel-1B images in Interferometric Wide Swath (IW) mode, which were acquired on descending orbits from 03 March 2018 to 22 January 2019. A WorldDEM Digital Surface Model (DSM) product was used to remove the topographic phase component. The results provided by both techniques showed a synoptic and informative view of the deformation process affecting the study area, with the detection of persistent trends of deformation on the crest, middle, and bottom sectors of the dam face until its collapse, as well as the settlements on the tailings. It is worth noting the detection of an acceleration in the displacement time-series for a short period near the failure. The maximum accumulated displacements detected along the downstream slope face were $-39 \mathrm{~mm}$ (SBAS) and $-48 \mathrm{~mm}$ (PSI). It is reasonable to consider that Sentinel-1 would provide decision makers with complementary motion information to the in situ monitoring system for risk assessment and for a better understanding of the ongoing instability phenomena affecting the tailings dam.
\end{abstract}

Keywords: Brumadinho; tailings dam; SBAS; PSI; Sentinel-1B

\section{Introduction and Context}

Mining is an important activity for the Brazilian economy, and iron ore is its main mineral commodity. The Vale S.A. mining company is the world's largest producer of iron ore and pellets, which are raw materials that are essential to the manufacture of steel. In 2018, the Brazilian trade balance hit USD 239.8 billion, with a surplus around USD 58.6 billion, and iron ore was related to $8.4 \%$ of the total value of exports. However, the Brazilian Gross National Product grew only $1.1 \%$ in 2019, after a better performance of $1.3 \%$ in 2018. One of the main causes of this reduction was the economic impact due to the failure of a tailings dam at the Córrego do Feijão mine, near Brumadinho city (Southeast of Brazil), which posted a loss to Vale S.A. of USD 7.402 billion [1]. Dam-I collapsed on 25 January 2019 and ranks as the 5th largest failure ever in recorded history, based on deaths, runout, and released waste material [2].

According to the Brazilian National Mining Agency (ANM), a total of 769 tailings dams were identified in Brazil at the beginning of 2019, with an accumulation of 3.5 billion of $\mathrm{m}^{3}$ of mining waste, 
and 84 tailing dams were raised using the upstream method [3]. This method is the cheapest but the least resilient of construction types, due to the fact that water is the primary instability agent [4]. The upstream method was the same related to the tailings dam of Fundão in Mariana (Brazil) that collapsed on 5 November 2015 [5] and Dam-I in Brumadinho.

Tailings dam failures are extremely detrimental to mine productivity. An evaluation of temporal trends in tailings dam incidents relative to the cyclical prices of mineral commodities was examined, and there appears to be a correlation between a mining boom cycle and an increased number of ruptures. Basically, during periods of price elevation of commodities, procedures for the licensing and construction of tailings dams are accelerated to take advantage of the price cycle, while during a lower price, there is a pressure to cut operational costs, with impact on the maintenance and security [6]. The most frequent causes of ruptures are overtopping and overflowing, slope foundation problems including settlement and slope instability, seepage and internal erosion (piping), structural failure due to the material used in the construction, and inappropriate maintenance [7]. Slope failures occur in a wide range of conditions and environments, and precursory signals prior to a rupture may not be so evident. Therefore, monitoring activities are mainly focused on measuring the ground movement for failure prediction and risk assessment.

Different procedures have been applied for the monitoring of tailings dams using geotechnical (piezometers, extensometers, shape array accelerometers, inclinometers, water level indicators, etc.) and non-geotechnical instruments (total station/reflecting prisms, video monitoring, laser scanner, ground stability radar, etc.). Lower cost instruments, such as total station/prisms and extensometers, are normally used for primary monitoring, but once instability has been detected, the ground-based radar is the best monitoring alternative, providing real-time data from fast movements $(\mathrm{mm} /$ day to few tens of $\mathrm{cm} /$ day) to very slow movements ( $\mathrm{mm} / \mathrm{month}$ to $\mathrm{mm} /$ year). However, despite the accuracy and reliability of data provided from these instruments, many precursory signals of ruptures cannot be detected due to several factors such as field measurements restricted to the points or sectors of the structure, fieldwork that can be costly and time consuming, adverse climatic conditions, restrictions to accessibility, inadequate field of view of the instrument, economical constraints, etc. Differential Interferometric Synthetic Aperture Radar (DInSAR) technology proved to be a valuable tool to monitor displacements in open pit mines and tailings dams [8-13], as well as hydric dams [14-16]. A recent paper was published to assess pre-disaster scenarios and direct causes of the tailings dam collapse in Brumadinho through the use of optical satellites and Sentinel-1 InSAR products [17]. Our study differs from this first contribution since it was focused on the detection of ground deformation patterns located along the downstream slope face before the dam-1 failure with a higher amount of measurement points through the use of two DInSAR techniques (SBAS and PSI) and a high-resolution DEM for topographic phase correction.

The advantages of DinSAR in relation to the previous procedures are that satellite monitoring can be made without fieldwork or ground equipment, providing a high accuracy of surface displacements, over a dense grid of measurement covering a large area and in all-weather conditions. However, since DInSAR is not a real-time technique, a complementary use with field monitoring schemes is necessary for operational planning and risk assessment. Particularly to tailings dams, the good results with DinSAR in Brazil were obtained using high-resolution SAR images. However, the small swath of most operational high-resolution systems implies a huge number of scenes to cover tailings dams located in many regions, a high cost of coverage, and limitations regarding data accessibility, which are the major obstacles for the operational use of this technology for systematic monitoring.

The advent of the Sentinel-1 SAR mission with two twin sensors (A and B) opened new possibilities for DInSAR applications with favorable characteristics: regional coverage due to a large swath (width $=250 \mathrm{~km}$ ), systematic and regular interferometric observation, rapid product delivery (typically in less than $3 \mathrm{~h}$ from scene acquisition), and free data access, thus providing the scientific community and public/private sectors interferometric data suitable for monitoring applications. The potential of Sentinel-1 interferometric data has been demonstrated for surface deformation monitoring $[18,19]$, 
landslide [20], continental mapping of deformation [21], and the prediction of catastrophic slope failures, including tailings dams [22], among other applications.

In this paper, we present and discuss results of the evaluation of Sentinel-1B data, Interferometric Wide swath (IW) mode and 12-day frequency of acquisition, aiming at detecting ground deformation prior to the catastrophic Dam-I failure. Since SBAS (Small BAseline Subset) [23] and PSI (Persistent Scatterer Interferometry) [24-26] techniques are two distinct conceptions of multi-interferogram algorithms, we adopted the use of both techniques in this investigation to optimize the extraction and to combine complementary information for monitoring ground displacement.

Analysis of the time failure prediction was performed from the SBAS and PSI ground displacements measurements, based on the inverse of the velocity method [27]. Early-warning analysis of slope failures in an open-pit mine using ground-based radar was conducted by [28] using this method. A precursor detection of landslide failure with Sentinel-1 data was achieved using the inverse velocity method in [22]. The potential of the inverse velocity method for predicting slope failure from satellite InSAR data in different scenarios was analyzed in [29], and the authors also explored the quality of the prediction based on the relative frequency distribution of the errors and the coefficient of determination $\mathrm{R}^{2}$ from the inverse velocity predictions.

\section{The Study Area}

Dam-I was part of the Córrego do Feijão mine at the Paraopeba Complex located in the Brumadinho municipality, Minas Gerais State, Brazil (Figure 1). Geologically, the Córrego do Feijão mine is located along the western border of Serra do Curral of the Quadrilátero Ferrífero (Iron Quadrangle), which is the main iron mineral province in Brazil. The area is related to the Piedade syncline that verges to NNW. The occurrence of high-grade magnetitic-martitic accumulation $(>64 \% \mathrm{Fe})$ of medium size ( $\approx 100 \mathrm{Mt})$ is controlled by the combination of folds and high-angle thrust faults [30]. The mine is characterized by the occurrence of ironstones known as itabirites from the plataformal sequence of the Minas Supergroup with Paleoproterozoic age (2.1-2.0 Ga). Massive and soft iron ores were formed by the supergene process acting during the Neogene over products associated with hydrothermal enrichments [31].
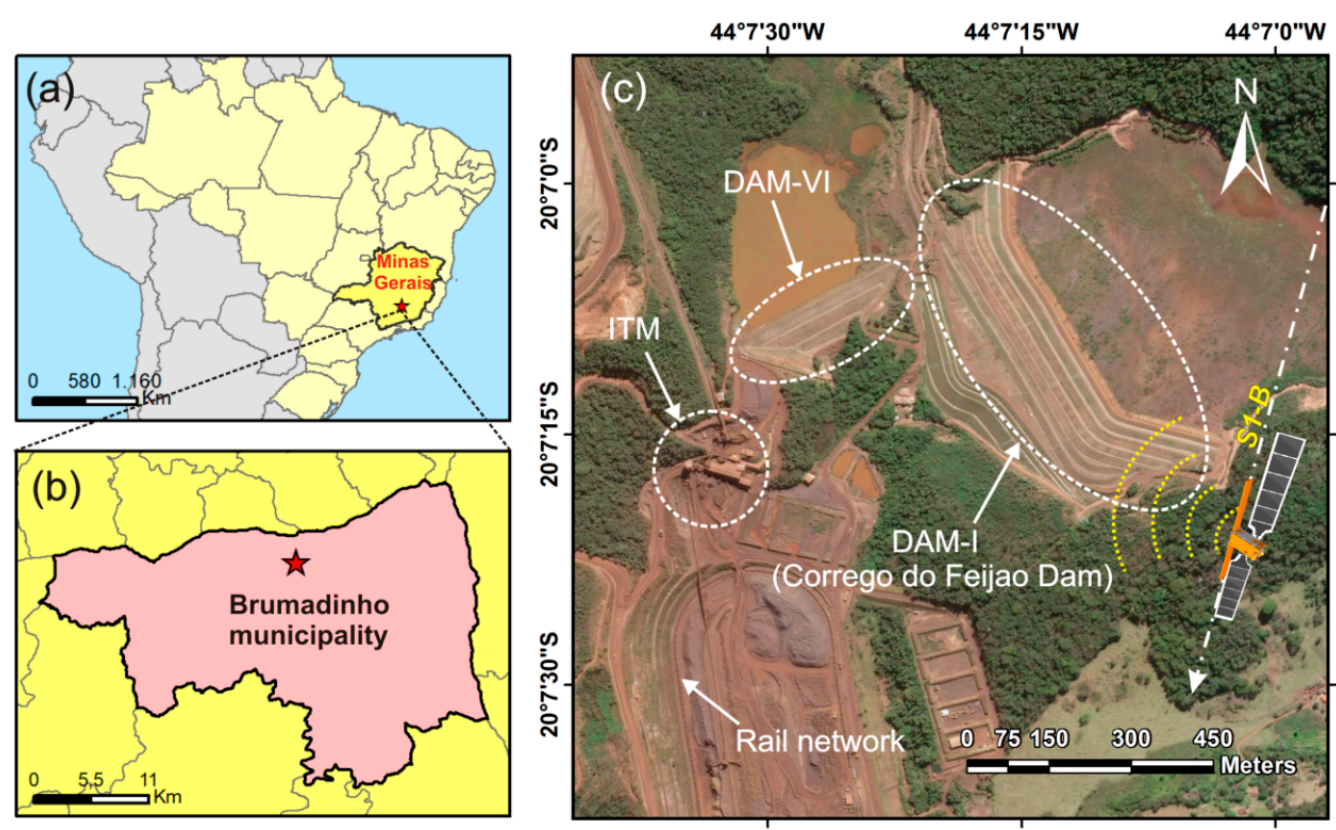

Figure 1. (a) Study area location in Minas Gerais state/Brazil; (b) Location of Paraopeba Iron Complex in the Brumadinho municipality; (c) Paraopeba Iron Complex showing tailings Dam I and hydric Dam VI, ancillary mining structures such as ore treatment installation (ITM), rail network, access roads, and a Sentinel-1B descending orbit ground track. 
The Córrego do Feijão mine was owned and developed by Ferteco Mineração S.A. until 27 April 2001, when it was acquired by Vale S.A. The production started at Córrego do Feijão mine in 1963 and Dam-I, placed in service in 1976, was specifically built to store its sinter tailings. In 2018, this mine produced 8.5 million tons of iron ore, which corresponded to $2 \%$ of the Vale's iron production [32]. Dam-I was constructed using the upstream method in 15 stages between 1976 and 2013. Using this method, the dam was constructed to a maximum height of $86 \mathrm{~m}$ and a crest length of $720 \mathrm{~m}$, with an intended maximum capacity of 12 million cubic meters, which were the capacity and height essentially attained at failure. Dam-I was inactive at the time of the failure, disposal operations having ceased in 2015, and it was in the process of being decommissioned.

\section{The Dam-I Rupture}

At about 12:28 p.m. local time on 25 January 2019, Dam-I suffered a failure, and within minutes the impounded material had liquefied, resulting in a catastrophic mudflow that traveled rapidly into the catchment downstream along the Córrego do Feijão stream (Figure 2). The waste material reached the confluence with Paraopeba River in hours and extending for more than $300 \mathrm{~km}$ toward the São Francisco River. Approximately 9.7 million cubic meters of waste material (almost approximately 75\% of the pre-failure volume) were involved in the failure. By the end of March 2020, a total of 259 people had been confirmed dead, and 11 bodies were still missing. The mudflow also destroyed some parts of the Córrego do Feijão district, including a nearby inn and several rural properties, as well as sections of a railway bridge and about $100 \mathrm{~m}$ of railway track. Agricultural areas in the valley below the dam were also damaged.
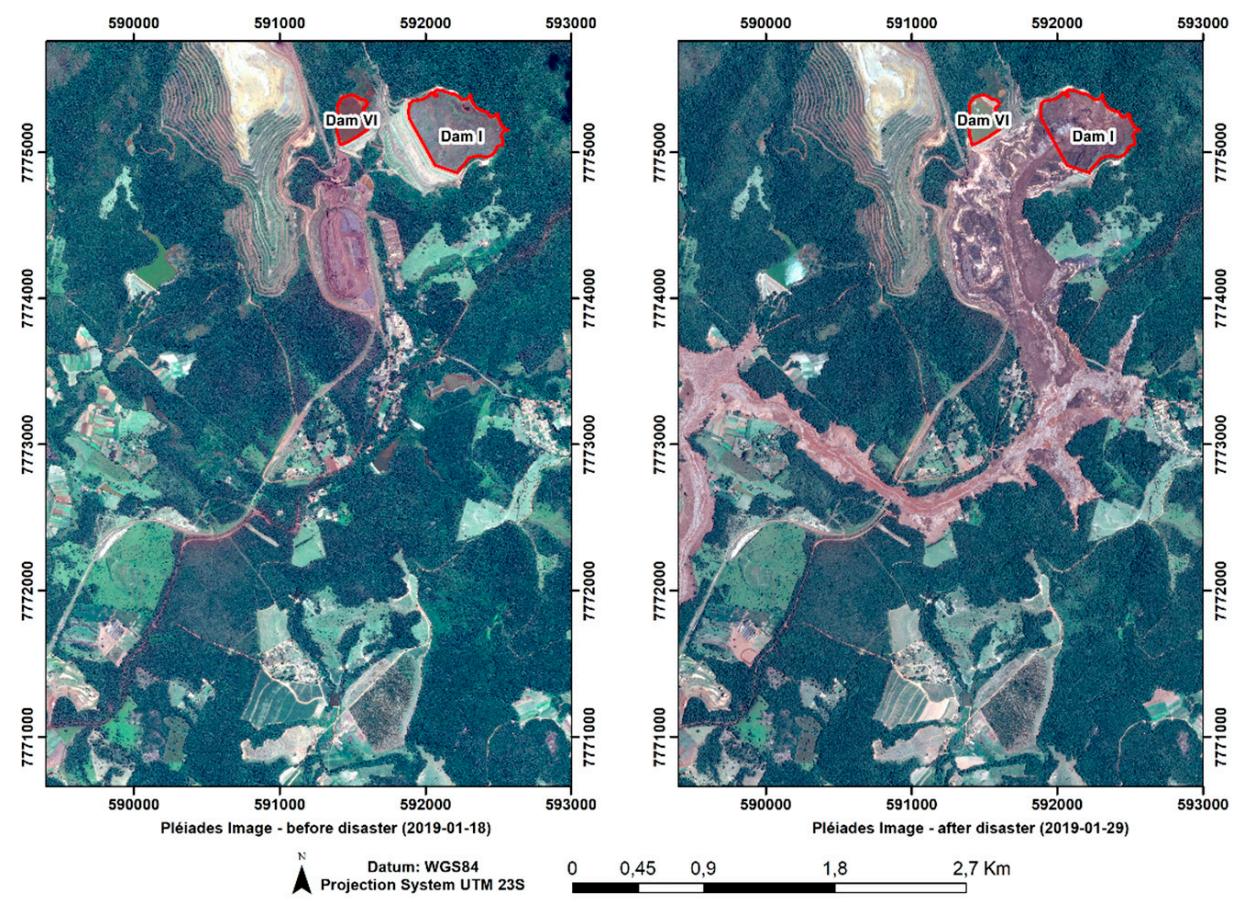

Figure 2. Pleiades satellite images taken just before and after the tragedy, showing the water from Dam-VI, the tailings from Dam-I, and the Corrégo do Feijão stream.

The water analysis from the Paraopeba River indicated high values of lead and mercury beyond the acceptable level, as well as the presence of nickel, cadmium, and zinc. In addition, a large area (around $269 \mathrm{ha}$ ) along watercourses was destroyed by the flux of waste material, including native Atlantic forest vegetation and permanent protection areas [33]. In the rescue of victims, the removal of mud was carried out by excavating machines and visual location of bodies by firefighters with sniffer 
dogs. Ground-penetrating radar (GPR) was also used aimed at mapping areas for future excavation and redirecting the rescue team [34].

A technical report produced by an expert panel contracted by Vale S.A. with full details and analyses on the Dam-I failure was presented on 12 December 2019 [35]. According to this report, analysis from the site-monitoring videos indicated that slope failure started from the dam crest and extended to an area just above the first raising. A mud wave up to $30 \mathrm{~m}$ was released, and the slope collapse was complete in less than $10 \mathrm{~s}$, with the stored tailings flowing out of the dam in less than $5 \mathrm{~min}$. The conclusions of the panel's report pointed out that a combination of six causes for the failure led to flow liquefaction of the tailings: the design resulting in a steep upstream slope; the water management within the tailings impoundment allowing water to get close to the crest; the setback in the design pushing the upper portions of the slope over weaker fine tailings; the lack of significant internal drainage resulting in a high water level in the dam; the high iron content in the waste material that was potentially very brittle if triggered to become undrained, and the intense season rainfall.

The monitoring system for Dam-I included a combination of instruments related to surface measurements technique at discrete points (total station/reflective prisms, inclinometers, piezometers), and over areas (Light Detection and Ranging-Lidar, seismograph, ground-based SAR), among other instruments. According to data from four seismographic stations near the study region, no vibrations were recorded on the day of the failure, and thus earthquakes and blastings were not triggers of the failure.

Even though a ground-based SAR was in operation at Dam-I, according to the panel's report, none of these instruments detected any significant clear trend of displacements, including the last months before the failure. A post-failure satellite InSAR analysis using data from distinct sources (Sentinel-1, TerraSAR-X, COSMO-Skymed) was also included in the final report covering the one-year period prior to failure. No information was provided regarding details of processing and modeling, which were used in this back-analysis. The results indicated slow and continuous small deformations in the range of 16 to $32 \mathrm{~mm} /$ year, particularly at the toe of the dam, starting from Mach/April 2018 with some acceleration during the wet season. Such deformations were interpreted as not being precursory signals of the failure.

\section{Materials and Methods}

\subsection{Satellite Data}

To carry out this research, 26 SLC images from Sentinel-1B were used, at IW mode, VV polarization, descending orbits, $32.56^{\circ}$ incidence angle, 12-day revisit, over a monitoring period of 11 months, from 16 March 2018 to 22 January 2019 (Table 1). The orbit files were updated using the European Space Agency (ESA) repository of Sentinel-1 auxiliary files (Precise Orbit Ephemerides files, POEORB) for all S1-B scenes in order to calculate the interferograms with more precise orbital data.

A WorldDEM DSM (Digital Surface Model) product provided by AIRBUS DEFENCE \& SPACE Company, with $12 \mathrm{~m}$ spatial resolution and absolute vertical accuracy better than $4 \mathrm{~m}$ (LE 90), was used to remove the topographic phase component during the DInSAR processing. This WorldDEM was obtained on 11 October 2018 before the Dam-I collapse. A WorldView-3 image, acquired on 6 February 2018, with $30 \mathrm{~cm}$ of resolution, was used as an image background for the analysis of the results.

\subsection{Methodological Approach}

Multi-temporal satellite SAR acquisitions have improved the capability for detecting temporal change of deformation phenomena. Time-series of SAR images gathered on the same area, with a small difference in the geometry acquisition, allows the generation of a stack of differential interferograms from which the analyses of the temporal ground displacement can be performed in the line of sight (LoS) direction. 
Table 1. Acquisition time of the Sentinel-1B data.

\begin{tabular}{cccc}
\hline Acquisition & Date & Acquisition & Date \\
\hline 1 & 20180316 & 14 & 20180831 \\
2 & 20180328 & 15 & 20180912 \\
3 & 20180409 & 16 & 20180924 \\
4 & 20180421 & 17 & 20181006 \\
5 & 20180503 & 18 & 20181018 \\
6 & 20180515 & 19 & 20181030 \\
7 & 20180527 & 20 & 20181111 \\
8 & 20180608 & 21 & 20181123 \\
9 & 20180620 & 22 & 20181205 \\
10 & 20180702 & 23 & 20181217 \\
11 & 20180714 & 24 & 20181229 \\
12 & 20180726 & 25 & 20190110 \\
13 & 20180819 & 26 & 20190122 \\
\hline
\end{tabular}

\subsubsection{DInSAR Analysis}

Time-series analysis based on multiple SAR acquisitions can be performed by a set of differential interferograms generated from the co-registered image stack. The phase components of each interferogram pixel are related to the topography, ground displacement, atmosphere, orbit error, and noise. A digital elevation model is used to remove the topographic phase component, which is the remaining phase related to the elevation model error.

Multi-referenced and master-referenced are the two ways to build a stack of interferograms, and different types of techniques are established to carry out the DInSAR analysis, the SBAS, and the PSI. While PSI extracts the phase change by analyzing stable and dominant scatterers (persistent), the SBAS technique allows measuring the surface movements related to distributed scatterers with homogeneous characteristics providing a better spatial coverage [36]. Considering natural terrain, where distributed scatterers are dominant, PSI techniques can exhibit a low density of measurement points (radar targets), while SBAS can show better spatial coverage. However, PSI analysis can be more accurate over the sparse grid of measured points (MPs), while the SBAS approach relies on which interferograms are considered, how they have been filtered, and the number of subsets selected. The higher the average coherence of the interferograms, the more similar the results of both techniques [37].

The SBAS technique explores the concept of Small BAseline Subsets [23], which seeks to extract information based on every single interferogram available. The algorithm accounts for spatial decorrelation phenomena, partitioning the dataset into several subsets, each consisting of the images acquired from orbits close to each other, discarding the interferograms corresponding to large baselines [38]. After phase unwrapping of the stack interferograms, the estimation of the physical quantities of interest, such as the topographic errors and the ground displacement, are achieved by applying the Single Value Decomposition (SVD) algorithm, which provides the average velocity of the displacement showing its temporal evolution.

In this work, SBAS analysis was performed with SARSCAPE software version 5.4.1, which was developed by the SARMAP AG Company [37]. A stack of 26 co-registered SLC images was used with a reference scene dated on 31 August 2018, which is located around the center of the time-series. Multi-look filtering using 2 looks in azimuth and 4 looks in range was applied in each SLC image. The stack of interferograms was built considering a constrain of $45 \%$ of the critical baseline $(4966.68 \mathrm{~m})$ and 80 days of temporal baseline, which showed to be the best setup to get measurements on the dam surface. Based on that, 129 interferograms were generated, wherein two of them were discarded due to phase unwrapping error during the inspection of the phase images. The spatial phase unwrapping processing of the interferograms was carried out by using the algorithm Minimum Cost Flow (MCF). We selected 13 Ground Control Points (GCP) in stable areas to estimate and remove the remaining phase constants and the phase ramp from the unwrapped phase stack. A low-pass filter 
covering a window of $1200 \times 1200 \mathrm{~m}$ was applied on the interferograms to remove the atmospheric phase components and perform the second inversion of the SBAS processing step. Figure 3 presents the relative spatial position of each time acquisition (green dots), and the solid lines represent the interferograms built according to the constraints describe above. The yellow dot represents the reference scene for the co-registration chosen on the middle of the time-series.

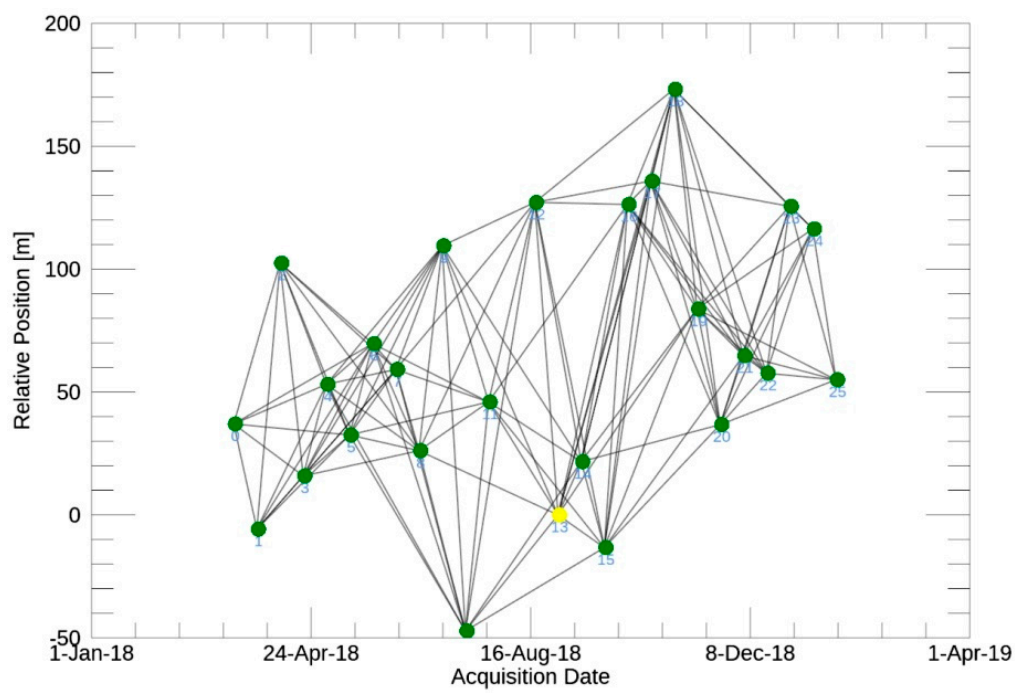

Figure 3. Interferometric pairs (solid lines) chose for SBAS (Small BAseline Subset) analysis; green dots correspond to the S1-B scenes and yellow dot corresponds to the reference scene for the co-registration (31 August 2018).

The PSI technique works on a stack of differential interferograms master-referenced in full resolution, using pixels within the resolution cell that exhibit stable amplitude backscattering properties (persistent scatterer, PS) and coherent phase [24-26]. At each pixel of the stack of the co-registered images, the PS candidates are estimated based on the amplitude dispersion index [24], as well as with pixels presenting low spectral diversity [25]. In general, a PS does not suffer spatial decorrelation, even when the baselines are larger than the critical one, allowing the use of long baselines [39]. It is normally assumed that the PS deformation rate is linear, because generally, the time dependence of the deformation is not known a priori. Deviations from this model (residual phase) are assumed to be due to the atmospheric phase contribution, the nonlinear phase displacement component, and the phase noise. The topographic phase error can be estimated practically as a linear function with the perpendicular baselines. The removal of the atmospheric-related phase can be accomplished by filtering the residual phase, taking advantage of the spatial correlation and temporal decorrelation of the atmospheric phase [40].

In this work, PSI analysis was performed using the Interferometry Point Target Analysis (IPTA) module approach [25] implemented in GAMMA RS software. The stack of 25 co-registered SLC images was built based on a master-referenced image acquired on 31 August 2018, considering the low perpendicular baseline dispersion nearly at the center of the time-series. The stack of 24 interferometric pairs presents a diversity of baseline values from -50 up to $180 \mathrm{~m}$, as shown in Figure 4 . In order to make the IPTA approach more efficient for PSI analysis with S1 IW data, we pre-estimated the height corrections and linear deformation rates, using a multi-reference stack with multi-look of $3 \times 1$ (3 in range), by performing the SVD algorithm to convert the multi-reference stack phases to a single reference time-series [41]. The phase related to the linear deformation rates and topographic phase errors previously found were subtracted in modulus $2 \pi$ from the PS phase, resulting in a residual wrapped phase. 


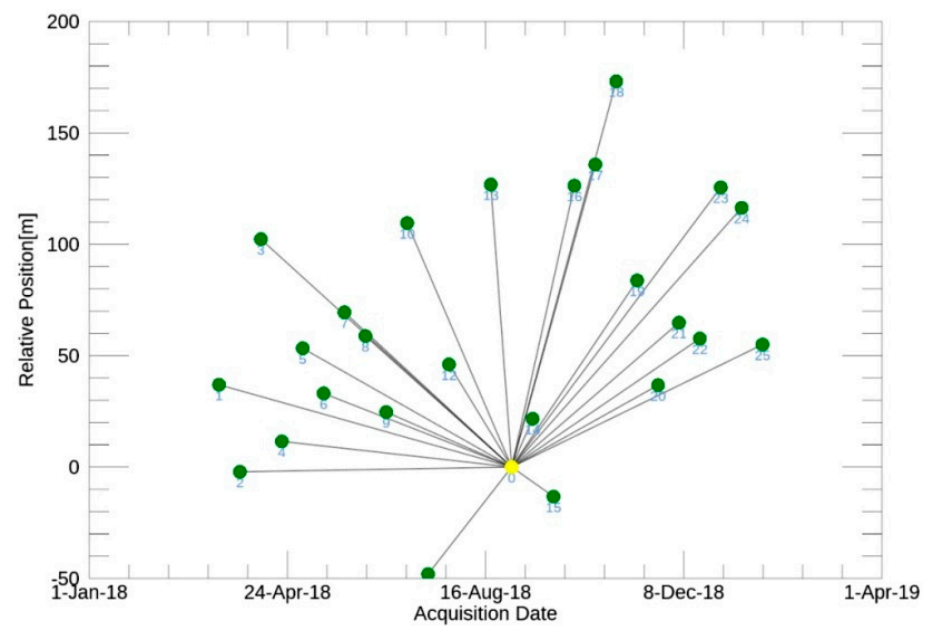

Figure 4. Interferometric pairs selected for PSI (Persistent Scatterer Interferometry) analysis; green dots correspond to the S1-B scenes and yellow dot corresponds to the reference scene (31 August 2018).

The residual ground displacement was estimated through a linear regression between the time and phase variation for each PS using the IPTA approach, considering limited deformation rates from - 30 up to $30 \mathrm{~mm} /$ year. The phase standard deviation from the linear regression error was selected as 1.35 radians, allowing the detection and rejection of points not suitable for PSI analysis. Atmospheric phase delay may account for most of the linear regression deviation (residues) related to the deformation. Its components were strongly attenuated by using a spatial filter of $200 \times 200$ samples, considering its characteristic of being spatially correlated and temporally uncorrelated. After removing the atmospheric phase component (residues spatially filtered) and noise phase (residues temporarily filtered), the remaining phase accounts for the residual linear and nonlinear deformation phase and topographic error. After a stepwise iteration of the PSI analysis, the outputs corresponding to the linear deformation rates and the topographic error of each PS were added to the multi-referenced stack analysis results previously mentioned, providing the final ground displacement estimation and the final topographic error, pointing out that only the PS that fulfilled the PSI processing constraint was considered [10].

\subsubsection{Failure Prediction}

Prediction of the time of a geomechanical failure is a major concern in the field of geological risk management. The interpretation of monitoring data is one of the main points of emphasis when trying to predict the time of geomechanical failure (Tf) or to assess the probability of an imminent collapse. Although a universal law that successfully accomplishes this goal for all the types of failure mechanisms does not exist, a good number of empirically derived methods and equations have been produced in the last decades. Among them, the effectiveness of the inverse velocity method has been demonstrated; it has become a widely applied tool for failure prediction, and its simplicity of use is its most powerful feature [27].

The accuracy of the analytical method is heavily influenced by the precision and frequency of the monitoring data [42]. The inverse velocity plot observed in [43] is in fact predominantly linear for landslides where the generation of a new shear surface and crack propagation are the dominant processes. In [44], they also found that the inverse velocity plot often approaches linearity, especially during the final stages of failure; they also highlighted the need to seek consistent linear trends in the data and their changes. The authors of [45] suggested that the linear fitting procedure should only include data following the identification of Onset of Acceleration (OOA) points. In addition, inferring suitable linear trend lines and deducing reliable failure predictions from inverse velocity plots are processes that may be hampered by the noise present in the measurements; therefore, data smoothing is a very important phase of inverse velocity analyses [27]. 
The $\mathrm{T}_{\mathrm{f}}$ prediction can be performed by extrapolating the trend of the inverse velocity-time plot toward zero; the point where the extrapolation of this plot intersects the time axis is an estimation of the time of failure. The coefficient of determination $\mathrm{R}^{2}$ on the inverse velocity plot and the relative frequency distribution of the predicted time and real failure times provide a measure of confidence of the prediction. This approach was evaluated in this research using the trend of slope displacement, velocity, and acceleration from SBAS and PSI results to determine whether detected deformations could anticipate the time of the Dam-I collapse.

A set of MPs localized on the face of the dam presenting significant ground displacement were selected to carry out the prediction analysis in both results. As pointed out in [27], the noise can hamper the prediction; the displacement time-series of each MP selected was filtered by a moving average window of 3 points. The identification of the OOA point on the displacement time-series is an important issue to perform the inverse velocity method; in our study we selected this point based on the observation of the SBAS and PSI results that presented a significant increment in the displacement gradient on the crest and the face of the dam.

\section{Results}

\subsection{SBAS Analysis}

SBAS measurements are differential with respect to a reference point and their dispersion, which is expressed by standard deviation of the estimated average displacement rates, and it increases with the distance to the reference point. The results of the deformation velocity $(\mathrm{mm} / \mathrm{y})$ can be visualized on a high-resolution Wordview color composite scene (Figure 5a). Positive values correspond to motion toward the satellite, and negative values correspond to motion away from the satellite. The highest values of deformation were recorded on the tailings (reddish colors), while lower values were detected for the top and middle sectors of the dam slope (yellowish colors). The bottom of the dam showed the lowest values of deformation (greenish color). The standard deviation of the deformation velocity (Figure 5b) is associated with a dominance of points with low values (greenish colors), i.e., points where the precision of the estimated displacement rate is higher, while sparse points with high values (reddish colors) are indicative of lower precision.

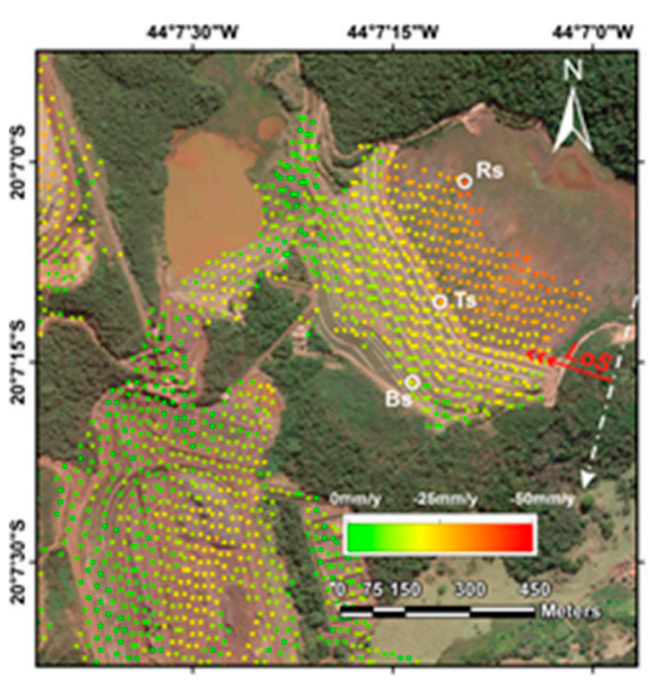

(a)

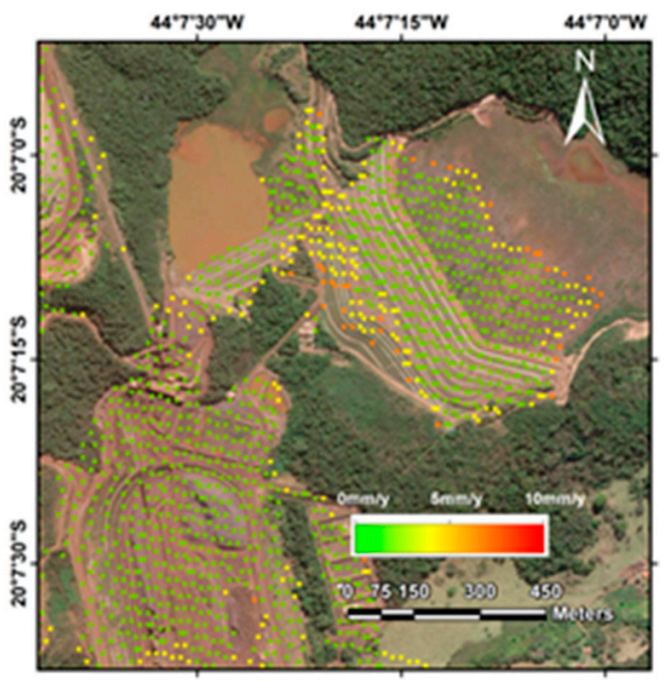

(b)

Figure 5. Map of the displacement rate (a) and the standard deviation (b) from the SBAS analysis; white circles represent the analyzed points in the dam reservoir $(R s)$, crest $(T s)$ and bottom face $(B s)$.

The SBAS results of the accumulated deformation $(\mathrm{mm})$ over a 3D perspective view of Dam-I using WorldDEM and a Worldview image are shown in Figure 6. It can be noticed that the maximum values 
of deformation occurred on the tailings (reddish dots) and on the crest of the dam, intermediate values on the dam slope (yellowish dots), while the stable regions (greenish dots) were spread in some parts of the dam slope and some mining structures. The results obtained showed a reasonable density of MPs with an average of $2259.24 \mathrm{MPs} / \mathrm{km}^{2}$ along the downstream dam face.

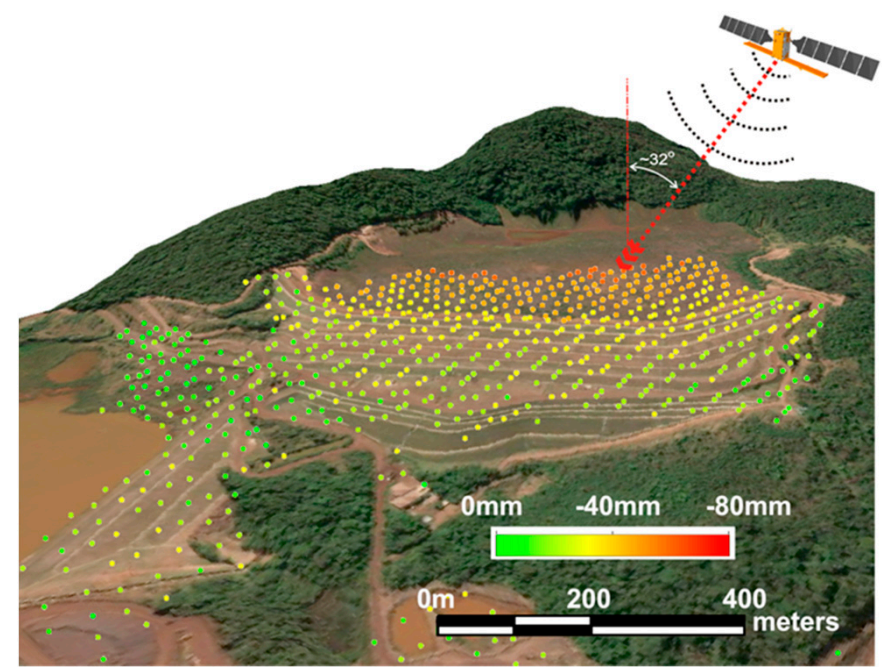

Figure 6. 3D view of Dam-I showing the accumulated displacement from SBAS processing analysis represented by colored dots.

The time-series displacements in the graphs of Figure 7 show the difference in deformation behavior for three selected points located at the downstream slope face slope and within the tailings. An almost similar deformation trend, with movements away from the satellite (negative values), was detected at the top and bottom of the dam. This trend is characterized by a first period with a slow linear displacement gradient from the beginning of the coverage up to late August 2018, which was followed by a phase of relative steadiness from August 2018 until the beginning of October 2018, and finally a second period with a slightly higher gradient of linear displacement up the last Sentinel-1 imagery on 22 January 2019 (three days before the failure). The profile for measured deformation in the tailings is also linear, with a higher gradient of acceleration as compared to the dam face sectors. An increase in the velocity of deformation was identified for the bottom sector and tailings from the beginning of December 2018 up to the end of the SAR coverage. Results with SBAS processing indicated a movement away from the sensor with a maximum accumulated displacement of $-39 \mathrm{~mm}$ (average rate of $-46 \mathrm{~mm} /$ year) for the top of the dam, of $-31 \mathrm{~mm}$ (average rate of $-36 \mathrm{~mm} /$ year) for the bottom of the dam, and $-79 \mathrm{~mm}$ average (average rate $=-92 \mathrm{~mm} /$ year) for the tailings.

Analyzing the SBAS deformation velocity for each sector of Figure 7, it can be noted that the crest deformation rate in sector $A$ was the highest $(-50.71 \mathrm{~mm} /$ year), while in sector $B$, the rate was low tending to stability; however, in sector $C$, the deformation velocity increases, almost reaching the value of sector A. In turn, the bottom of the dam presented a moderate value of deformation velocity in sector A, the stability of sector B, and the greatest deformation acceleration $(-60.59 \mathrm{~mm} / \mathrm{y})$ for sector C. The linear regression of the base data showed a stronger acceleration in sector $C$; this is probably due to the fact that the dam swelled on the slope before collapsing. Table 2 shows the SBAS deformation rate for each sector defined in Figure 7. 


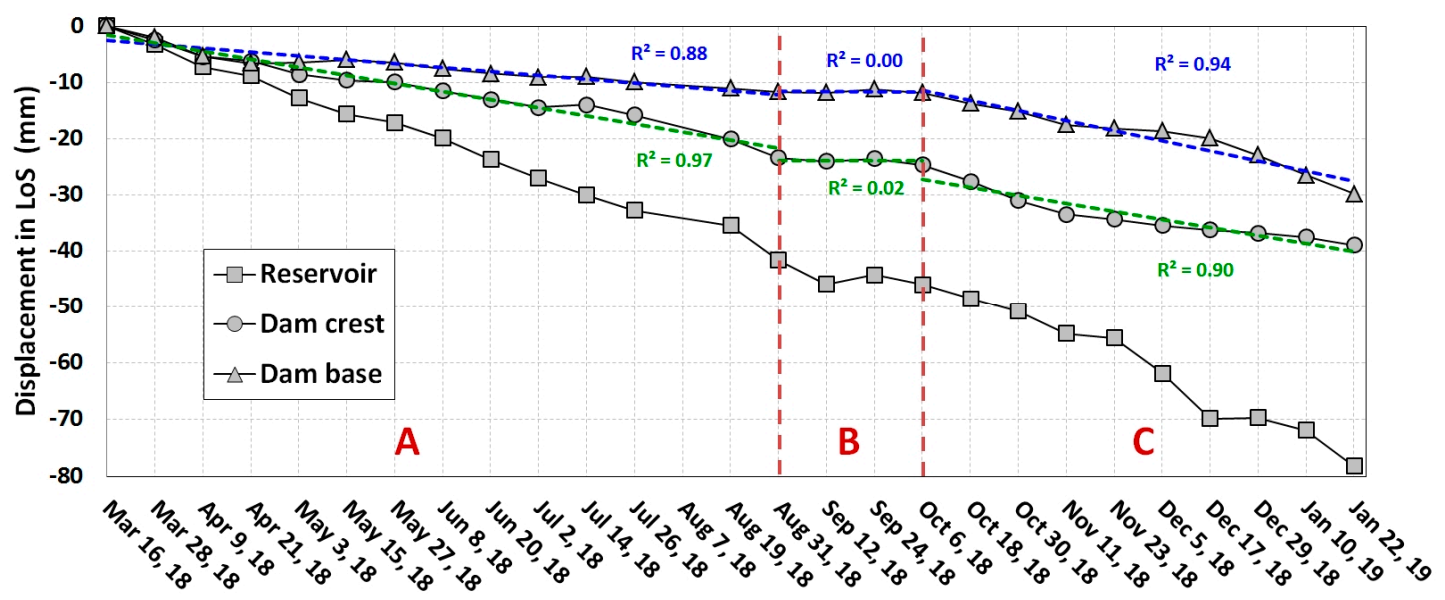

Figure 7. Time-series of SBAS line of sight (LoS) displacements for selected measured points (MPs) located at three selected points of the dam, as presented in Figure 5a, showing the highest cumulative displacements for the entire period of monitoring and the linear regression of the data (letters A, B, and $C$ are the displacement trends as discussed in the text).

Table 2. SBAS deformation rate for each sector.

\begin{tabular}{ccc}
\hline & SBAS: Crest (Ts) & SBAS: Bottom (Bs) \\
\hline Sector A & $-50.71 \mathrm{~mm} / \mathrm{y}$ & $-25.25 \mathrm{~mm} / \mathrm{y}$ \\
Sector B & $-13.78 \mathrm{~mm} / \mathrm{y}$ & $-2.74 \mathrm{~mm} / \mathrm{y}$ \\
Sector C & $-48.07 \mathrm{~mm} / \mathrm{y}$ & $-60.59 \mathrm{~mm} / \mathrm{y}$ \\
\hline
\end{tabular}

\subsection{PSI Analysis}

The result of the PSI analysis presents a pattern of ground displacement rate as shown in Figure 8a, and its corresponding standard deviation of the velocity is shown in Figure 8b. The displacement in the tailings can be attributed to settlements, and the maximum accumulated value during the monitoring period was $-67 \mathrm{~mm}$. A pattern of ground deformation can be noticed spread on the slope face of Dam-I, with a maximum accumulation of $-48 \mathrm{~mm}$. The standard deviation of the deformation rates depends on the distance from the reference point, which in this case was about $1400 \mathrm{~m}$ from the Dam-I center, but it also depends on the deformation behavior in terms of rate and nonlinearity. Figure $8 \mathrm{~b}$ shows higher values in the tailing reservoir, close to $8 \mathrm{~mm} /$ year, and values from 2 to $6 \mathrm{~mm} /$ year along the downstream slope face of Dam-I.

The distribution of the MPs with accumulated deformations depicted over a 3D perspective view of using WorldDEM and a Worldview image is presented in Figure 9. It can be observed that the maximum values of deformations, around $-70 \mathrm{~mm}$, were detected on the tailings (reddish dots). Some sectors of the dam face presented MPs with deformations up to $-40 \mathrm{~mm}$ (orangish dots). Stability was detected for some sectors of the mining structures (greenish dots). The results obtained showed a reasonable density of MPs with an average of $1174.80 \mathrm{MPs} / \mathrm{km}^{2}$ on the slope face. 


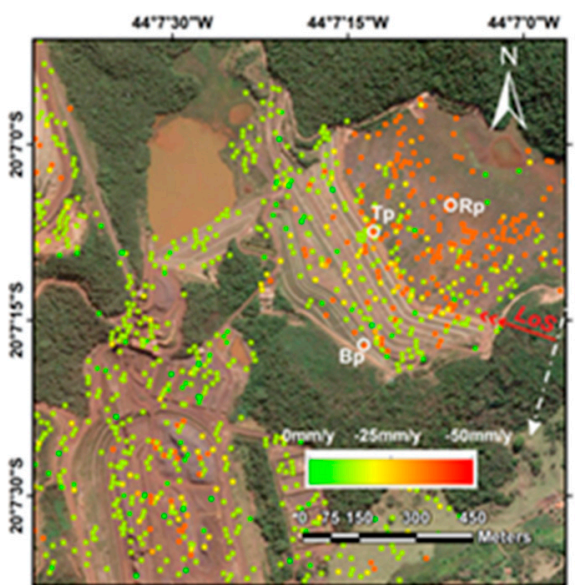

(a)

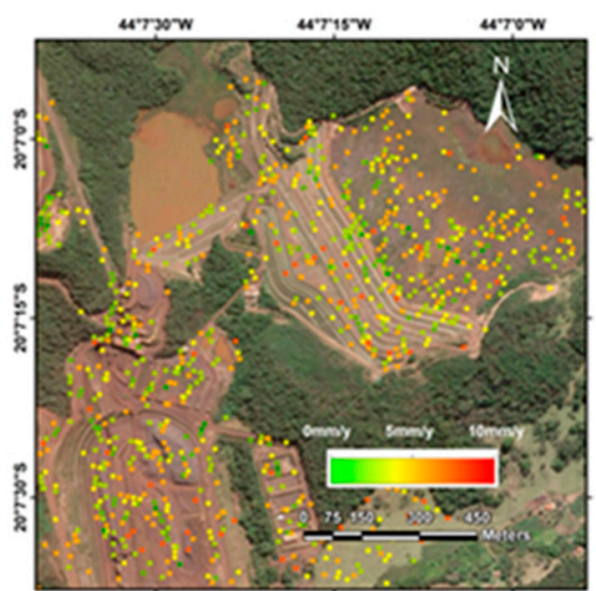

(b)

Figure 8. Maps of the displacement rate (a) and the standard deviation (b) from the PSI analysis; white circles represent the analyzed points in the dam reservoir $(R p)$, crest $(T p)$ and bottom face $(B p)$.

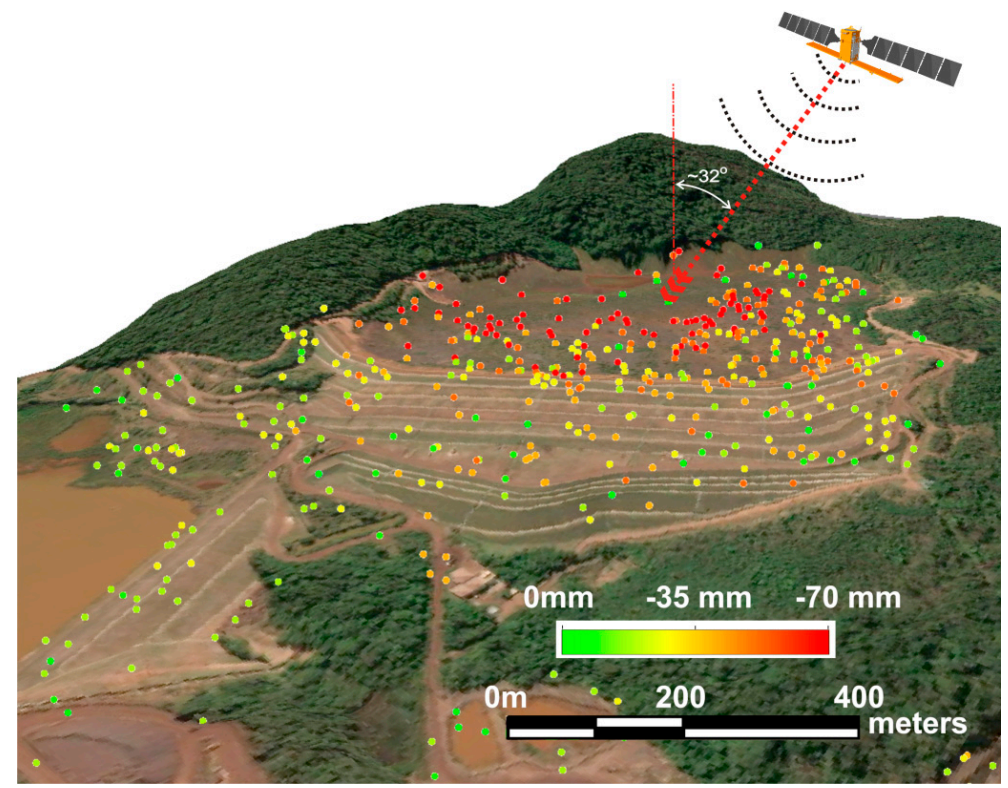

Figure 9. View in 3D of Dam-I showing the accumulated displacement from PSI analysis represented by colored dots.

Time-series displacements in the graphs of Figure 10 are related to three selected points with the maximum LoS cumulative displacements, which are located at the bottom and top of the face slope and within the tailings. Differences in the deformation profiles can be seen for the dam face, which are given by a first gradient of continuous linear deformation from the beginning of monitoring until late August 2018, a second period of relative steadiness from 31 August 2018 up to 6 October 2018, and a last period of more intense deformation from the beginning of October 2018 until the end of the coverage (22 January 2019). During this last period, an increase of acceleration was recorded particularly for the bottom of the dam starting from the beginning of December 2018 up to the end of the SAR coverage. The deformation profile for the tailings is characterized by a linear, continuous, and more intense gradient of acceleration when compared to the points located at the face slope. The maximum cumulative displacements and average rates with PSI processing for the crest, bottom, and tailings were $-42 \mathrm{~mm}$ (rate $=-53 \mathrm{~mm} /$ year), $-48 \mathrm{~mm}(-50 \mathrm{~mm} /$ year $)$, and $-67 \mathrm{~mm}(-78 \mathrm{~mm} /$ year $)$, respectively. 


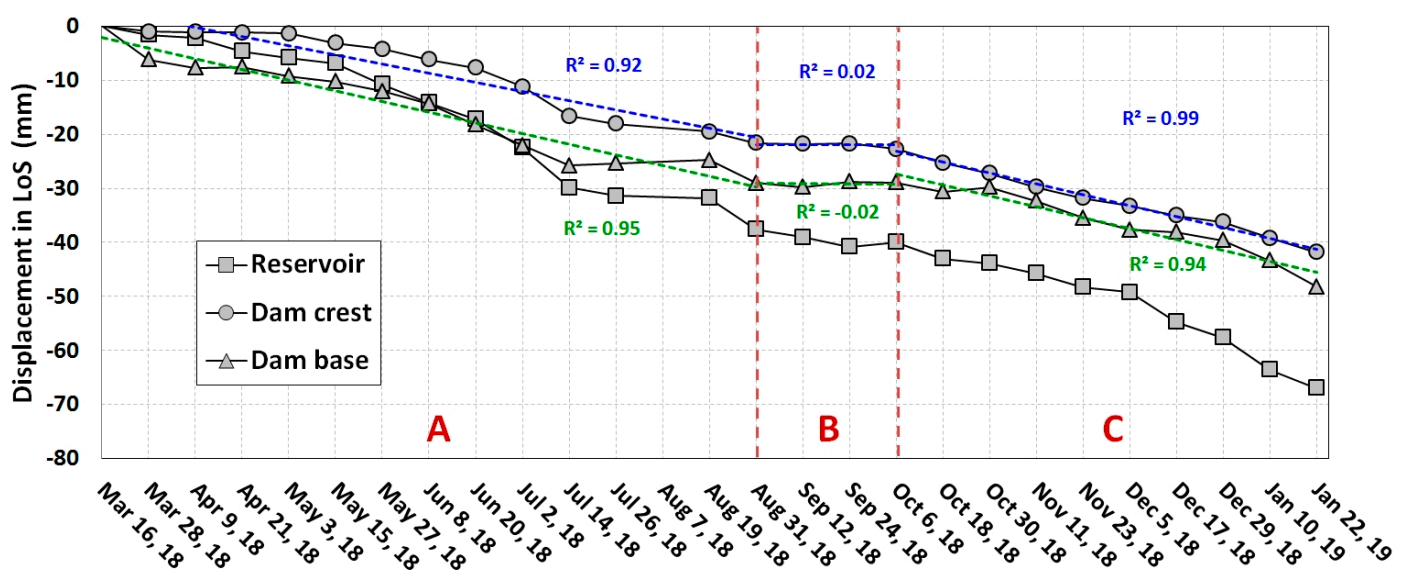

Figure 10. Time-series PSI LoS displacements for three selected points located at three sectors of Dam-I as presented in Figure 8a showing the highest cumulative displacements for the entire period of monitoring and the linear regression of the data (letters $\mathrm{A}, \mathrm{B}$, and $\mathrm{C}$ are the deformation trends as discussed in text).

The PSI deformation velocity behavior of sectors of Figure 10 showed the highest values of deformation rate for sector $C$, with similarity between the crest $(-64.49 \mathrm{~mm} / \mathrm{y})$ and the base dam $(-65.10 \mathrm{~mm} / \mathrm{y})$ values. For sector $\mathrm{A}$, the crest value $(-46.97 \mathrm{~mm} / \mathrm{y})$ was lower than the dam base $(-63.08 \mathrm{~mm} / \mathrm{y})$. In its turn, the base dam value for sector A $(-63.08 \mathrm{~mm} / \mathrm{y})$ were similar to those of sector C $(-64.49 \mathrm{~mm} / \mathrm{y})$. This similar trend can be observed by the regression for crest and base behavior of this period, showing that they were practically parallels. Table 3 shows the PSI deformation rate for each sector delimited in Figure 10.

Table 3. PSI deformation rate for each sector.

\begin{tabular}{ccc}
\hline & PSI: Crest (Tp) & PSI: Base (Bp) \\
\hline Sector A & $-46.97 \mathrm{~mm} / \mathrm{y}$ & $-63.08 \mathrm{~mm} / \mathrm{y}$ \\
Sector B & $-11.48 \mathrm{~mm} / \mathrm{y}$ & $-0.84 \mathrm{~mm} / \mathrm{y}$ \\
Sector C & $-64.49 \mathrm{~mm} / \mathrm{y}$ & $-65.10 \mathrm{~mm} / \mathrm{y}$ \\
\hline
\end{tabular}

\subsection{Failure Prediction Analysis}

In an attempt to predict the date of the dam failure based on SBAS and PSI results, 21 MPs (not coincident) located on the crest and along the dam face presenting meaningful ground displacement were selected to perform the inverse of the slope velocity versus time procedure. The first analysis was performed on the average of these 21 MPs of both results, as shown in Figures 11a and 12a for SBAS and PSI, respectively; 17 December 2018 was considered our OOA point based on the displacement behavior shown in Figure 7, Figure 10, Figure 11a, and Figure 12a, where most graphs show the inflection point in the displacement, which is considered the onset of the final acceleration phase. In order to estimate the date of the rupture, a linear regression was applied on the inverse of the velocity data, and its intersection with the time axis provided the predicted time failure (Tpf). The coefficient of determination $\mathrm{R}^{2}$ shows how adjusted the linear regression was with the inverse velocity data. Figure $11 \mathrm{~b}$ shows both graphs, the inverse of the velocity and the linear regression, with an adjusted $\mathrm{R}^{2}$ equal to 0.88 , and with the interception found 10 days after the actual time failure (Taf). It is worth pointing out that this result was obtained for the average displacement calculated over $21 \mathrm{MPs}$. 


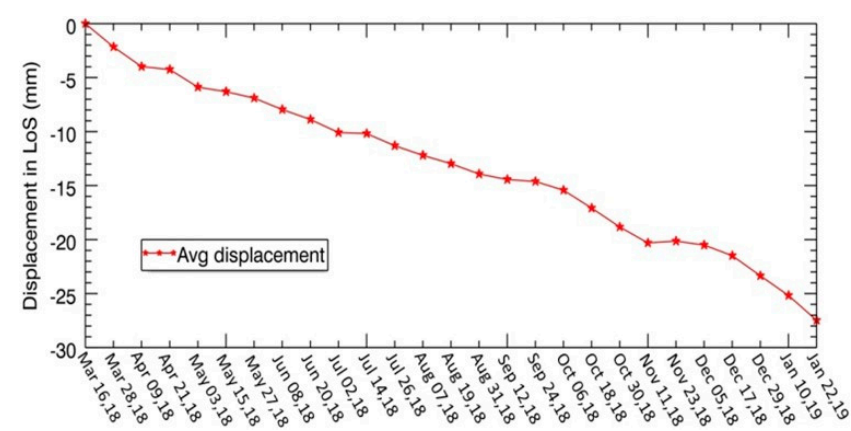

(a)

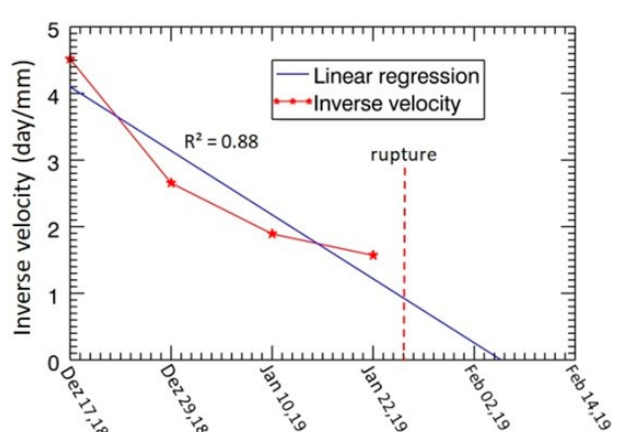

(b)

Figure 11. SBAS average displacement (a) and inverse of the velocity graph with linear regression (b).

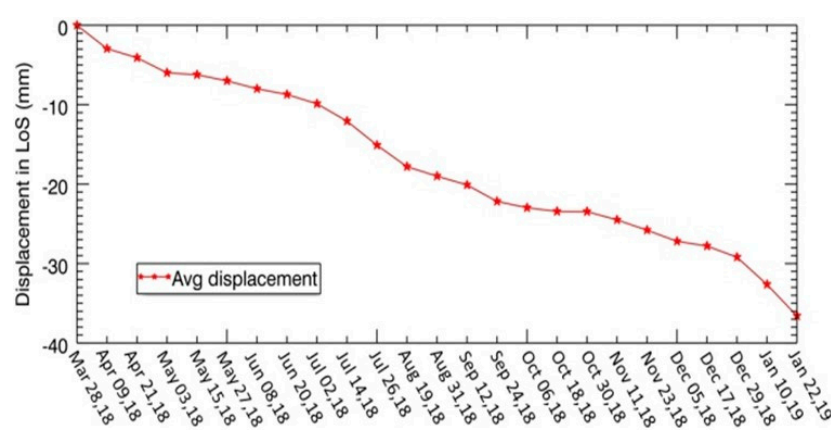

(a)

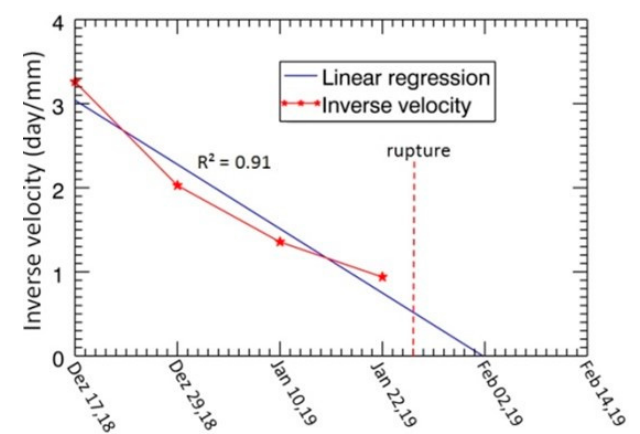

(b)

Figure 12. PSI average displacement (a) and inverse of the velocity graph with linear regression (b).

The same analysis as previously described was performed based on the average of 21 MPs from the PSI results. The profile of the averaged displacements can be seen in Figure 12a. Figure 12b exhibits the graphs of the inverse of the velocity and the linear regression, with an adjust $\mathrm{R}^{2}$ equal to 0.91 , with the interception occurring 8 days after the rupture.

The results of the inverse of the velocity analysis shown in Figures $11 \mathrm{~b}$ and $12 \mathrm{~b}$ reveal that the tendency of the inverse velocity plot does not agree with the linear regression, despite the high value of $\mathrm{R}^{2}$; this behavior can be related to the low sampling frequency (12 days of the Sentinel-1 revisit time), the nature of the final acceleration phase (Dam-I suffered an abrupt rupture event according to the panel's report [35]), and the number of displacement samples analyzed.

The analysis was also conducted at each of the separate 21 MPs from the SBAS results, using the inverse velocity method, which provided the predict time failure (Tpf) for each point. By subtracting the Tpf from the actual time of failure (Taf), we got a distribution of the prediction errors, as shown in Figure 13a, where a positive error indicates that the failure occurred earlier than the estimate. The $\mathrm{R}^{2}$ coefficients distributions from the inverse velocity predictions can be seen in Figure 13b.

The same analysis using PSI results related to 21 MPs with meaningful ground displacement, which are located on the crest and along the dam face, showed a distribution of the prediction errors as illustrated in Figure 14a; the $\mathrm{R}^{2}$ coefficients distribution is shown in Figure $14 \mathrm{~b}$.

The relative frequency distribution of the prediction errors (Tpf-Taf) shown in Figures 13a and 14a reveal that the accelerating trends of displacement from 17 December 2018 to 22 January 2019 were not strong enough to predict the failure time. The reliability of the predictions appears to be quite low in both results; the distribution of the errors is visibly scattered, although in the neighborhood of 5 days from the rupture, PSI analysis presents a maximum frequency of two repetitions. Despite the low confident prediction, the $\mathrm{R}^{2}$ distribution shown in Figures $13 \mathrm{~b}$ and $14 \mathrm{~b}$ presents quite good adjustments with the linear regressions and low standard deviation. 


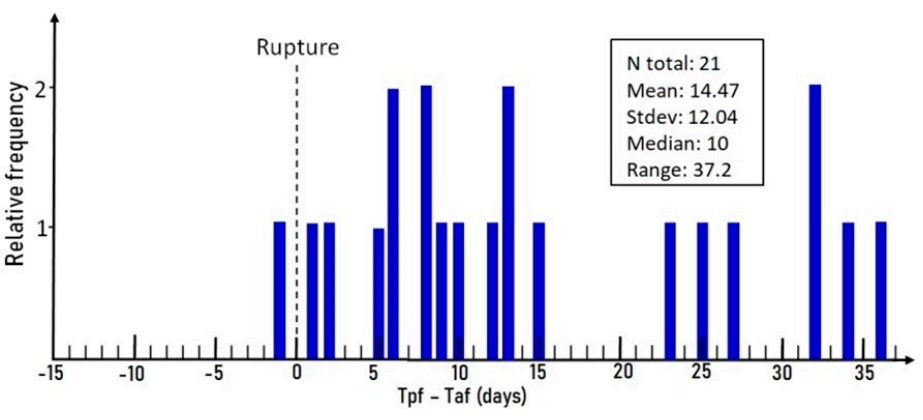

(a)

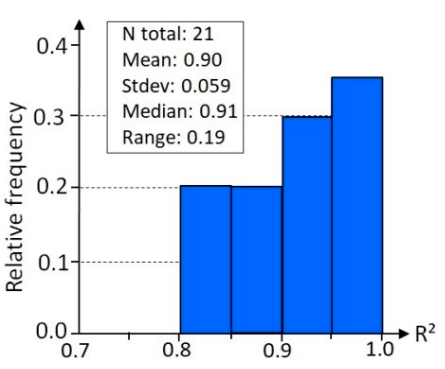

(b)

Figure 13. SBAS relative frequency distribution of the errors (a) and $\mathrm{R}^{2}$ coefficient from the inverse velocity predictions $(\mathbf{b})$.

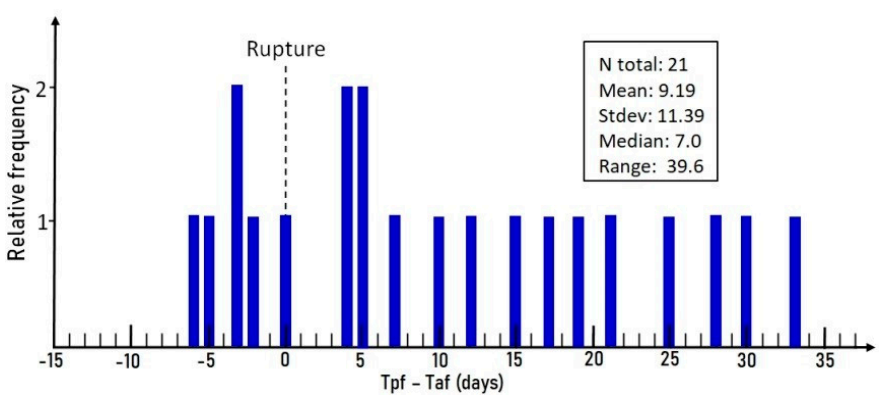

(a)

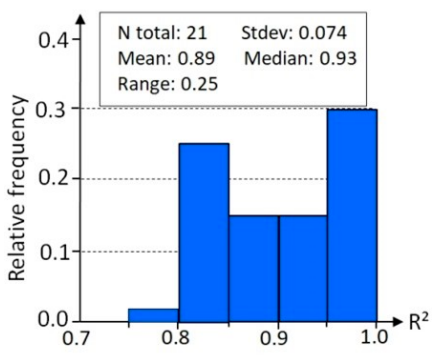

(b)

Figure 14. PSI relative frequency distribution of the errors (a) and $R^{2}$ coefficient from the inverse velocity predictions $(\mathbf{b})$.

Figure 15 shows the PSI and SBAS results and the location of two MPs, Bs and Bp, representing respectively the SBAS and PSI points with the highest accumulated deformation values on the bottom of the dam. Their geographic positions were different for both SBAS and PSI, which were separated by $68 \mathrm{~m}$, due to the different target identification characteristics for which these techniques work. The behavior of these two points was analyzed in Figure 16 in relation to the precipitation occurred in the period from 03 March 2018 to 22 January 2019.

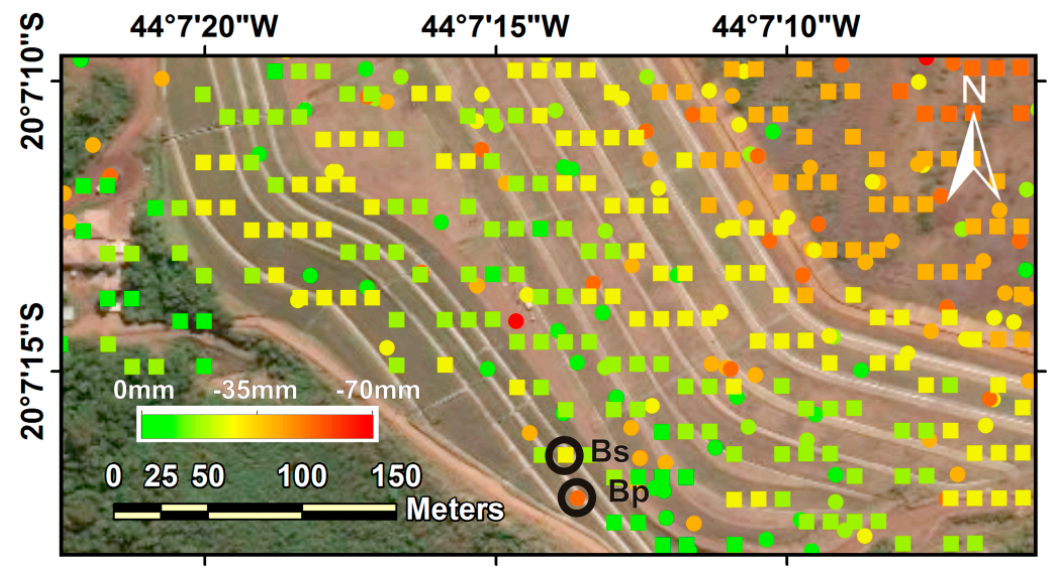

Figure 15. SBAS and PSI results combined and the locations of Bs and Bp points (black circles), which are the SBAS and PSI points with the highest accumulated deformation values on the dam bottom; SBAS MPs are represented by square symbols, and PSI MPs are represented by round symbols. 


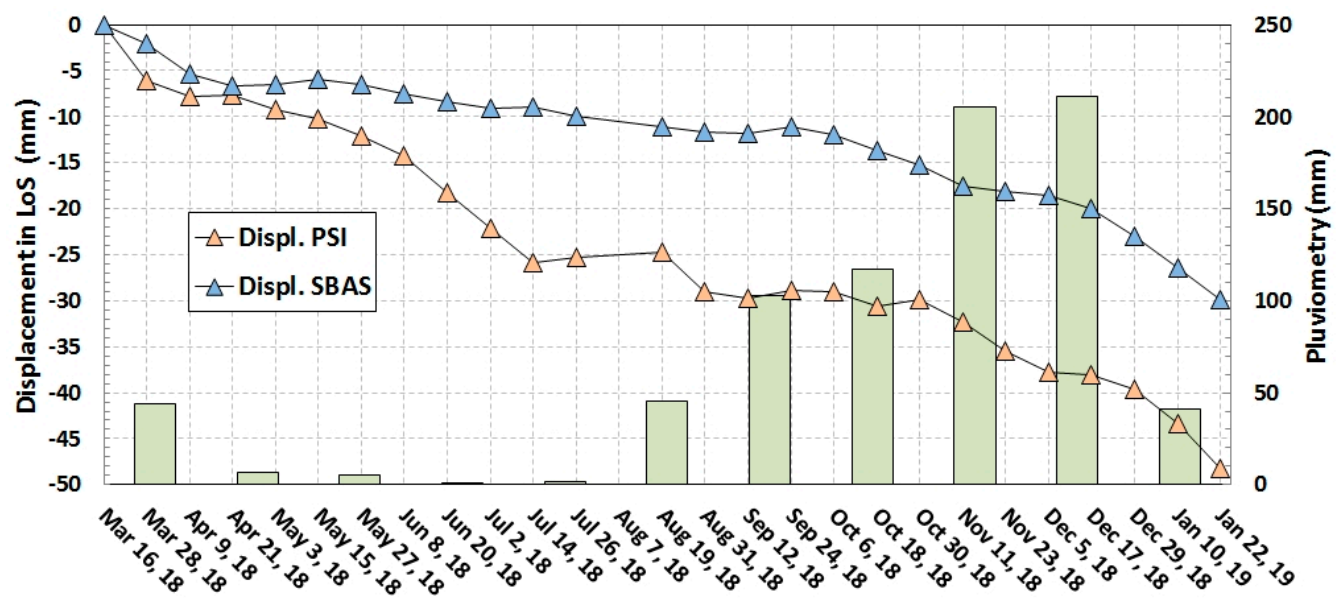

Figure 16. Time-series of LoS displacement for two selected points located at the bottom of the dam showing the maximum cumulative displacements for the entire monitoring period and the accumulated pluviometric data.

An automatic meteorological station (\#310900606A) from the Brazilian National Center for Monitoring and Early Warning of Disasters (CEMADEN) in the Brumadinho city, close to the study area, provided the rainfall information during the period of the Sentinel-1B coverage. The accumulated displacements behavior for the MPs Bs and Bp, not coincidentally located at the bottom of the dam (Figure 15), and the mensal accumulated precipitations are shown in Figure 16. It can be seen that there is a clear influence of the changes in the pluviometry favoring the acceleration of the movements: during the dry seasons (April to August), the variation of deformation is small or tending to stabilization, while during the wet seasons (September-March), an increment of deformation velocity can be noticed. According to [46], a review of rainfall data also revealed a gradual increment of precipitation for the quarter period of the wet season (October-December) in 2018 when compared to the previous three years (62\% compared to $2015,28 \%$ compared to 2016 , and $15 \%$ compared to 2017 ). The accelerating trend of deformation for the PSI point (Bp) during the dry season can be related to deformation on the slope, as partly recorded by the ground-based SAR and survey data in Appendix D [35]. Due to the separation between Bs and Bp and the multi-looking processing performed in SBAS processing, this behavior was not detected with the Bs point during the dry period.

Pearson's correlation tests were performed between the paired variables of the accumulated deformation and the accumulated precipitation, for the dry and rainy seasons. We found that for the SBAS technique, the correlation was significant with values of -0.9622 for the crest of the dam and -0.9415 for the bottom of the dam during the rainy season, while the results for the PSI technique verified values of -0.9802 for the crest of the dam and -0.9237 for the bottom of the dam.

For the dry season period, the correlations were lower between the variables, with values of -0.8273 for PSI and -0.9030 for SBAS for the crest of the dam. For the bottom of the dam, the correlation value was -0.6651 SBAS and -0.7138 for the PSI. Thus, the greatest correlations were observed between displacements and rainfall during the rainy season.

\section{Discussion}

SBAS and PSI analysis provided, for each measurement point, a time-series of deformation describing the behavior of LoS displacement velocity over the entire period of monitoring. More precisely, the temporal series of displacements showed an almost similar behavior for the crest and bottom of the slope face, with three deformation phases given by a first linear acceleration gradient (March 2018-August 2018), a period of relative stabilization (August 2018-October 2018), and a higher gradient of acceleration (October 2018-January 2019). The deformation trend for measurements points within the tailings is characterized by a linear and continuous gradient of acceleration along 
the monitoring period. The maximum accumulated displacements and velocity rates were higher for PSI than for SBAS. An increase of velocity for the last 40-day period before the failure was detected for the bottom of the dam with displacement variations of $10 \mathrm{~mm}$ (SBAS) and $11 \mathrm{~mm}$ (PSI). Finally, the deformation trend for measurements points within the tailings is characterized by a linear and continuous gradient of acceleration along the monitoring period with both techniques. The negative values of the motions are indicative of the projection of the displacement vector affecting the measurement point moving away from the satellite and sensitive to range variations along to the LoS, which is orientated to WNW (Sentinel-1 descending mode).

The most relevant information regarding the field monitoring system within the context of this research was published as an Appendix (D) of the panel's report [35]. It is related to the use of the slope stability ground-based IBIS-FM SAR developed by IDS GeoRADAR [47,48], which was installed at a distance of the slope face ranging from 730 to $1160 \mathrm{~m}$ (i.e., the lower and upper part of the dam, respectively). Despite the short monitoring period (October 2019-January 2019), a deformation pattern was detected using the very slow movement capacity of the instrument. The results of measurements for five small areas located in the lower and middle part of the dam showed a similar trend of motions toward the sensor with displacements reaching up to $4 \mathrm{~mm}$ for a two-week period prior to the failure (9 to 24 January 2019). This displacement rate is out of the minimum detectable velocity for the system according to $[47,48]$.

The numeric comparison of deformation values measured by both systems was not carried out due to various aspects (viewing geometry, spatial resolution, time-scan, etc.), and particularly taking into account that the look azimuths for the ground-based SAR (NE-looking) and Sentinel-1 (WNW-looking) are quite distinct; in addition, we had Sentinel data only in descending orbit and thus could not extract vertical and horizontal displacement. However, they are concordant regarding the presence of movements along the dam face, with an acceleration in the short period near the failure. It is worth noting that the deformations provided by Sentinel-1 with LoS range lengthening (away from the satellite) and ground-based SAR with LoS range shortening (toward the sensor), for common sectors of the dam face, are compatible with the motion components of the rupture, which were oriented to WSW.

The prediction analysis of the date failure carried out with 21 measured points on the crest and on the face of Dam-I, based on SBAS and PSI results, can be interpreted as follows: the average displacement shown in Figures 11a and 12a presents a persistent increase of the displacement prior to the rupture, which was more accentuated after 17 December 2018. The analysis of the inverse of the velocity conducted with the average data predicts the failure date about 10 days and 8 days after the disaster, for SBAS for PSI analysis, respectively, as can be seen in Figures $11 \mathrm{~b}$ and $12 \mathrm{~b}$. The analysis of the inverse of the velocity conducted with these 21 points in both results presents the frequency distribution of the prediction errors according to the histograms shown in Figures 13a and 14a. The reliability of the predictions appears to be quite low in both results; the distribution of the errors is visibly scattered, although in the neighborhood of 5 days from the rupture, PSI analysis presents a maximum frequency of two repetitions. The $R^{2}$ distribution shown in Figures $13 \mathrm{~b}$ and $14 \mathrm{~b}$ presents quite good adjustments with the linear regressions, which were calculated from the inverse velocity data, with low standard deviation. Based on the prediction distribution errors found with both techniques' results, despite the good $\mathrm{R}^{2}$ distribution in both cases, it would not have been possible to identify the date of failure with reasonable confidence.

\section{Conclusions}

In this research, the tailings Dam-I collapse occurred on 25 January 2019 were analyzed through the use of two independent DInSAR techniques (SBAS and PSI) applied to 26 descending IW mode images acquired by Sentinel-1B from 3 March 2018 to 22 January 2019. The main purpose of this analysis was to verify evidence of ground displacements and - if detected — to characterize its spatio-temporal evolution. Both techniques that take into account different models of ground scattering mechanisms revealed 
signals of deformation over the slope face and tailings in the months prior to the rupture. In general, SBAS technique has provided a better spatial coverage of measurements points along the downstream slope face when compared to the PSI results. However, despite a lower density of good radar targets, the PSI technique presented higher values of accumulated displacements. In this sense, SBAS and PSI techniques can be considered as complementary, since they provided convergent results that maximized the spatial coverage and displacement detection.

By analyzing the temporal series of SBAS and PSI measurements for the upper and the lower face of the dams, an almost similar deformation behavior was characterized with three distinct phases: a first phase with a continuous linear acceleration gradient (March-August 2018), with maximum rates of -50.71 and $-25.25 \mathrm{~mm} / \mathrm{y}$ on the top and the base of the dam, respectively for SBAS and -46.97 and $-63.08 \mathrm{~mm} / \mathrm{y}$ on the top and the base, respectively for PSI, a steadiness phase (August-September 2018) and a final phase with linear acceleration again (October 2018-January 2019), with maximum rates of -48.07 and $-60.59 \mathrm{~mm} / \mathrm{y}$ on the top and the base, respectively for SBAS and -64.49 and $-65.10 \mathrm{~mm} / \mathrm{y}$ on the top and the base, respectively for PSI. It can be noticed that in the third phase, the agreement between the techniques results are more accentuated.

An increment of deformation velocity for the bottom part of the dam was detected from the middle of December 2018 until the last scene acquisition, three days before the rupture. The values of the maximum accumulated displacements in this period for the dam face were in the range of -30 to $-39 \mathrm{~mm}$ (SBAS), and -42 to $-48 \mathrm{~mm}$ (PSI). The deformation in the tailings can be attributed to settlements, and the maximum accumulated displacements during the monitoring period were -79 (SBAS) and $-67 \mathrm{~mm}$ (PSI). All the displacement measurements were associated with negative values (motion away from the satellite) and are projections along the WNW oriented LoS of the 3D displacement vector affecting the slope face, whose rupture was WSW oriented. The relationship between rainfall variation and acceleration of displacements, particularly during the wet period beginning in October 2018, is consistent with the presence of water as one of the main driving factors for the instability of the structure.

The predictability of the failure was also investigated through the inverse velocity method using measured points from both techniques. Despite the coefficient of determination $\mathrm{R}^{2}$ being considered good (higher than $80 \%$ ) as a quality index of the regressions, the confidence of these predictions was considered low, since the errors' distributions (before and after the rupture) were not centered near the failure time with large gaps between the time predictions and the actual failure time.

Three final remarks may be derived from the results. Firstly, the Sentinel-1 nominal resolution is $4 \times 20 \mathrm{~m}$ (IW-mode), and even with this relative poorer spatial resolution when compared to commercial systems, such as TerraSAR-X $(3.3 \times 1.7 \mathrm{~m}$ resolution, SM mode $)$ and COSMO-SkyMed $(3 \times 3 \mathrm{~m}$ resolution, $\mathrm{SM}$ mode), it was enough to provide good radar targets suitable for this particular application. Secondly, Dam-I suffered an abrupt rupture event according to the panel's report. The low frequency of Sentinel-1 acquisition can only provide detailed motion information under a synoptic view of the surface deformation phenomena affecting the area of interest, as well as its spatio-temporal evolution. However, it is not a real-time technique such as ground-based radar, which is a well-established technology to detect the fast deformation of the escalating failure process. Even though satellite DInSAR techniques were not synergistically used with in situ observations during the monitoring period prior to the failure and the reliability of orbital predictions was low, it is reasonable to consider that Sentinel-1 would still provide decision makers with independent motion information for risk awareness and for a better understanding of ongoing instability phenomena affecting the structure. Finally, due to the large number of tailings dams in vast regions of Brazil, unmonitored or with poorly monitoring systems, the use of Sentinel-1 with suitable requirements for DinSAR applications proved to be an effective tool for monitoring and risk assessment. There exists a significant demand in Brazil for deformation information related to tailings dam situations for a number of reasons (legal obligations, safety, environmental monitoring, etc.). Sentinel-1 interferometric data can be used for the systematic tracking of ground deformation of mining structures, providing 
key information to make crucial decisions regarding risks, or even mitigation, repairs, or emergency response in circumstances that can lead to loss of life and damages to infrastructure and the environment. In this sense, the use of the higher frequency acquisition of the Sentinel- 1 constellation (6 days revisit) improves the possibility to track motions with short time lengths.

Author Contributions: F.F.G. and J.C.M. wrote the manuscript and were in charge of SAR processing. W.R.P. wrote the manuscript and carried out the analysis of the area and the data interpretation. C.G.d.O. provided data from Pleiades 1A images. All authors have read and agreed to the published version of the manuscript.

Funding: This research received no external funding.

Acknowledgments: The authors are grateful for the support of VISIONA TECNOLOGIA ESPACIAL S.A. and AIRBUS DEFENCE \& SPACE companies for providing the WorldDEM DSM and Pleiades 1A images for the research and also to Thiago Gonçalves Rodrigues for providing the Figure 2. The National Council for Scientific and Technological Development (CNPq) is also acknowledged for a grant (CNPq Process: \# 304091/2019-7) received by the third author during the investigation. The paper benefited significantly from the journal's reviewers.

Conflicts of Interest: The authors declare no conflict of interest.

\section{Abbreviations}

The following abbreviations are used in this manuscript:

$\begin{array}{ll}\text { DInSAR } & \text { Differential Interferometric SAR } \\ \text { PSI } & \text { Persistent Scatterer Interferometry } \\ \text { IPTA } & \text { Interferometry Point Target Analysis } \\ \text { SBAS } & \text { Small BAseline Subset } \\ \text { MCF } & \text { Minimum Cost Flow } \\ \text { SVD } & \text { Singular Value Decomposition } \\ \text { LoS } & \text { Line-of-Sight }\end{array}$

\section{References}

1. Vale, S.A. Financial Results 2019. Available online: http://Saladeimprensa.vale.com/em/Paginas/Articles. aspx?r=Financial_Results_2019\&s=Finance\&rID=1323\&sID=5 (accessed on 13 March 2020).

2. WMTF. World Mining Tailings Failure Brumadinho. 2020 Draft Report. Available online: https: //worldminetailingsfailures.org/corrego-do-feijao-tailings-failure-1-25-2019/ (accessed on 14 March 2020).

3. ANM Tailings Dam Classification and Safety Plan 2019. Available online: http://www.anm.gov.br/assuntos/ barragens/pasta-classificacao-de-barragens-demineracao/plano-de-seguranca-de-barragens (accessed on 9 June 2019).

4. Kossoff, D.; Dubbin, W.E.; Alfredsson, M.; Edwards, S.J.; Macklin, M.G.; Hudson-Edwards, K.A. Mine Tailings Dams: Characteristics, Failure, Environmental Impacts, and Remediation. Appl. Geochem. 2014, 51, 229-245. [CrossRef]

5. Morgenstern, N.R.; Vick, S.G.; Viotti, C.B.; Watts, B.D. Fundão Tailings Dam Review Panel: Report on the Immediate Causes of the Failure of the Fundão Dam; Samarco, S.A., Vale, S.A., Eds.; BHP Brasil Ltd. Belo Horizonte, Brazil: August 25, 2016; p. 76. Available online: http://fundaoinvestigation.com/the-panel-report/ (accessed on 18 May 2018).

6. Davies, M.; Martin, T. Mining market cycles and tailings dam incidents. In Proceedings of the 13th International Conference on Tailings and Mine Waste, Banff, AB, Canada, 1-4 November 2009; Available online: http://www.infomine.com/library/publications/docs/Davies2009.pdf (accessed on 31 November 2014).

7. Alves, C.; Carneiro, S.; Santos, A. Management of Tailings Dam at Samarco Mineração S.A. Presented at the Brazilian Ministry of Mines and Energy, Brasília, Brazil, 13 December 2017; Available online: http: //www.mme.gov.br/documents/20182/5e3fa655-7e22-d835-973e-e3f1f8f83547 (accessed on 7 May 2020). (In Portuguese).

8. Hartwig, M.E.; Paradella, W.R.; Mura, J.C. Detection and monitoring of surface motions in active mine in the Amazon region, using persistent scatterer interferometry with TerraSAR-X satellite Data. Remote Sens. 2013, 5, 4719-4734. [CrossRef] 
9. Paradella, W.R.; Ferretti, A.; Mura, J.C.; Colombo, D.; Gama, F.F.; Tamburini, A.; Santos, R.A.; Novalli, F.; Galo, M.; Camargo, P.O.; et al. Mapping surface deformation in open pit iron mines of Carajás Province (Amazon Region) using an integrated SAR analysis. Eng. Geol. 2015, 193, 61-78. [CrossRef]

10. Mura, J.C.; Paradella, W.R.; Gama, F.F.; Silva, G.G.; Galo, M.; Camargo, P.; Silva, A. Monitoring of Non Linear Ground Movement in an Open Pit Iron Mine Based on an Integration of Advanced DInSAR Techniques Using TerraSAR-X Data. Remote Sens. 2016, 8, 409-427. [CrossRef]

11. Gama, F.F.; Cantone, A.; Mura, J.C.; Pasquali, P.; Paradella, W.R.; Santos, A.R.; Silva, G.G. Monitoring subsidence of open pit iron mines at Carajás Province based on SBAS interferometric technique using TerraSAR-X data. Remote Sens. Appl. Soc. Environ. 2017, 8, 199-211.

12. Mura, J.C.; Gama, F.F.; Paradella, W.R.; Negrão, P.; Carneiro, S.; Oliveira, C.G.; Brandão, W.S. Monitoring the vulnerability of the dam and dykes in Germano iron mining after the collapse of the tailings dam of Fundão (Mariana-MG, Brazil) using DInSAR techniques with TerraSAR-X data. Remote Sens. 2018, 10, 1507. [CrossRef]

13. Gama, F.F.; Paradella, W.R.; Mura, J.C.; Oliveira, C.G. Advanced DInSAR analysis on dam stability monitoring: A case study in the Germano mining complex (Mariana, Brazil) with SBAS and PSI techniques. Remote Sens. Appl. Soc. Environ. 2019, 16, 100267. [CrossRef]

14. Emadali, L.; Motagh, M.; Haghighi, M.H. Characterizing post-construction settlement of the Masjed-Soleyman embankment dam, Southwest Iran, using TerraSAR-X SpotLight radar imagery. Eng. Struct. 2017, 143, 261-273. [CrossRef]

15. Milillo, P.; Bürgmann, R.; Lundgren, P.; Salzer, J.; Perissin, D.; Fielding, E.; Biondi, F.; Milillo, G. Space geodetic monitoring of engineered structures: The ongoing destabilization of the Mosul dam, Iraq. Sci. Rep. 2016, 6, 37408. [CrossRef]

16. Al-Husseinawi, Y.; Li, Z.; Clarke, P.; Edwards, S. Evaluation of the stability of the Darbandikhan Dam after the 12 November 2017 Mw 7.3 Sarpol-e Zahab (Iran-Iraq border) earthquake. Remote Sens. 2018, 10, 1426. [CrossRef]

17. Rotta, L.H.S.; Alcântara, E.; Park, E.; Negri, R.G.; Lin, Y.N.; Bernardo, N.; Mendes, T.S.G.; Sousa Filho, C.R. The 2019 Brumadinho tailings dam collapse: Possible cause and impacts of the worst human and environmental disaster in Brazil. Int. J. Appl. Earth Obs. Geoinf. 2020, 90, 102119. [CrossRef]

18. Devanthéry, N.; Crosetto, M.; Monserrat, O.; Cuervas-Gonzales, M.; Crippa, B. Deformation monitoring using Sentinel-1 SAR data. In Proceedings of the 2nd International Electronic Conference on Remote Sensing (SCIforum), 22 March-5 April 2018; Volume 2. online. [CrossRef]

19. Strozzi, T.; Antonova, S.; Günther, F.; Mätzler, E.; Gonçalo Vieira, G.; Wegmüller, U.; Westermann, S.; Bartsch, A. Sentinel-1 SAR Interferometry for Surface Deformation Monitoring in Low-Land Permafrost Areas. Remote Sens. 2018, 10, 1360. [CrossRef]

20. Béjar-Pizarro, M.; Notti, D.; Mateos, R.M.; Ezquerro, P.; Centolanza, G.; Herrera, G.; Bru, G.; Sanabria, M.; Solari, L.; Javier Duro, J.; et al. Mapping Vulnerable Urban Areas Affected by Slow-Moving Landslides Using Sentinel-1 InSAR Data. Remote Sens. 2017, 9, 876. [CrossRef]

21. Lanari, R.; Bonano, M.; Buonanno, S.; Casu, F.; De Luca, C.; Fusco, A.; Manunta, M.; Manzo, M.; Onorato, G.; Zeni, G.; et al. Continental scale SBAS-DInSAR processing for the generation of Sentinel-1 deformation time series within a cloud computing environment: Achieved results and lessons learned. In Proceedings of the EGU General Assembly 2020, 4-8 May 2020. EGU2020-17944. [CrossRef]

22. Intrieri, E.; Raspini, F.; Fumagalli, A.F.; Lu, P.; Conte, D.C.; Farina, P.; Allievi, J.; Ferretti, A.; Casagli, N. The Maoxian landslide as seen from space: Detecting precursors of failure with Sentinel-1 data. Landslides 2018, 15, 123-133. [CrossRef]

23. Berardino, P.; Fornaro, G.; Lanari, R.; Sansosti, E. A new algorithm for surface deformation monitoring based on small baseline differential SAR interferograms. IEEE Trans. Geosci. Remote Sens. 2002, 40, 2375-2383. [CrossRef]

24. Ferretti, A.; Prati, C.; Rocca, F. Permanent scatterers in SAR interferometry. IEEE Trans. Geosci. Remote Sens. 2001, 39, 8-20. [CrossRef]

25. Werner, C.; Wegmuller, U.; Strozzi, T.; Wiesmann, A. Interferometric point target analysis for deformation mapping. In Proceedings of the IEEE International Geoscience and Remote Sensing Symposium (IGARSS 2003), Toulouse, France, 21-25 July 2003; Volume 7, pp. 4362-4364. 
26. Hooper, A.; Zebker, H.; Segall, P.; Kampes, B. A new method for measuring deformation on volcanoes and other natural terrains using InSAR Persistent Scatterers. Geophys. Res. Lett. 2004, 31, L23611.

27. Carlá, T.; Intrieri, E.; Di Traglia, F.; Nolesini, T.; Gigli, G.; Casagli, N. Guidelines on the use of inverse velocity method as a tool for setting alarm thresholds and forecasting landslides and structure collapses. Landslides 2017, 14, 517-534. [CrossRef]

28. Carlá, T.; Farina, P.; Intrieri, E.; Botsialas, K.; Casagli, N. On the monitoring and early-warning of brittle slope failures in hard rock masses: Examples from an open-pit mine. Eng. Geol. 2017, 228, 71-81. [CrossRef]

29. Carlà, T.; Intrieri, E.; Raspini, F.; Bardi, F.; Farina, P.; Ferretti, A.; Colombo, D.; Novali, F.; Casagli, N. Perspectives on the prediction of catastrophic slope failures from satellite InSAR. Sci. Rep. 2019, 9, 14137. [CrossRef]

30. Sanglard, J.; Rosière, C.A.; Santos, J.O.S.; Mcnaughton, N.J.; Fletcher, I. The structure of the western segmento of Serra do Curral, Iron Quadrangle and the tectonic control of the compact accumulation of iron high content. Geol. USP-Sci. Ser. 2014, 13, 81-95. (In Portuguese) [CrossRef]

31. Rosière, C.A.; Rolim, V.K. Iron formation and associated high-grade iron ore: The iron ore of Brazil, geology, metallogenesis and economy. In Mineral Resources in Brazil, Problems and Challenges; Brazilian Academy of Sciences: Rio de Janeiro, Brazil, 2016; pp. 2-45. (In Portuguese)

32. Cavallini, M. The Mine that Hosts the Brumadinho Dams Responds for $2 \%$ of Vale Iron Production, Veja Raio-X. 2019. Available online: https://g1.globo.com/economia/noticia/2019/01/28/minaqueabriga-barragem-em-brumadinho-responde-por-2-da-producao-da-vale-veja-raio-x.ghtml (accessed on 28 January 2019).

33. Cionek, V.M.; Alves, G.H.Z.; Tófoli, R.M.; Rodrigues-Filho, J.L.; Dias, R.M. Brazil in the mud again: Lessons not learned from Mariana dam collapse. Biodivers. Conserv. 2019, 28, 1935-1938. [CrossRef]

34. Porsani, J.L.; Jesus, F.A.N.; Stangari, M.C. GPR survey on an iron mining area after the collapse of the tailings dam I at the Córrego do Feijão mine in Brumadinho-MG, Brazil. Remote Sens. 2019, 11, 860. [CrossRef]

35. Robertson, P.K.; Melo, L.; Williams, D.J.; Wilson, G.W. Report of the Expert Panel on the Technical Causes of the Failure of Feijão Dam 1. 2019, p. 71. Available online: https://bdrb1investigationstacc.z15.web.core. windows.net/assets/Feijao-Dam-I-Expert-Panel-Report-ENG.pdf (accessed on 3 January 2020).

36. Osmanoglu, R.; Sunar, F.; Wdowinski, S.; Cabral-Cano, E. Time Series Analysis of InSAR data: Methods and trends. ISPRS J. Photogramm. Remote Sens. 2016, 115, 90-102.

37. SARscape Technical Description. Available online: http://www.sarmap.ch/pdf/SARscapeTechnical.pdf (accessed on 5 July 2020).

38. Lanari, R.; Mora, O.; Manunta, M.; Mallorquí, J.J.; Berardino, P.; Sansosti, E. A small-baseline approach for investigating deformations on full-resolution differential SAR interferograms. IEEE Trans. Geosci. Remote Sens. 2004, 42, 1377-1386. [CrossRef]

39. Crosetto, M.; Monserrat, O.; Cuervas-Gonzales, M.; Devanthéry, N.; Crippa, B. Persistent Scatterer Interferometry: A review. ISPRS J. Photogramm. Remote Sens. 2016, 115, 79-89. [CrossRef]

40. Kampes, B.M. Radar Interferometry: Persistent Scatterer Technique; Springer: Berlin/Heidelberg, Germany, 2006.

41. Wegmuller, U.; Werner, C.; Strozi, T.; Wiesmann, A.; Frey, O.; Santoro, M. Sentinel-1 Support in the GAMMA Software. Procedia Comput. Sci. 2016, 100, 1305-1312. [CrossRef]

42. Voight, B. A relation to describe rate-dependent material failure. Science 1989, 243, 200-203. [CrossRef]

43. Petley, D.N.; Bulmer, M.H.; Murphy, W. Patterns of movement in rotational and translational landslides. Geology 2002, 30, 719-722. [CrossRef]

44. Rose, N.D.; Hungr, O. Forecasting potential rock slope failure in open pit mines using the inverse-velocity method. Int. J. Rock Mech. Min. Sci. 2007, 44, 308-320. [CrossRef]

45. Dick, G.J.; Eberhardt, E.; Cabrejo-Liévano, A.G.; Stead, D.; Rose, N.D. Development of an early-warning time-of-failure analysis methodology for open-pit mine slopes utilizing ground-based slope stability radar monitoring data. Can. Geotech. J. 2014, 52, 515-552. [CrossRef]

46. Ministry of Economy (ME). Analysis Report of the Work Accident on the Dam-1 Failure in Brumadinho (MG). 2019; 237p. Available online: https://sit.trabalho.gov.br (accessed on 30 July 2020). 
47. Leoni, L.; Coli, N.; Farina, P.; Coppi, F.; Michelini, A.; Costa, T.A. On the Use of Ground-Based Synthetic Aperture Radar for Long-Term Slope Monitoring to Support the Mine; Geotechnical Team, Australian Centre for Geomechanics: Perth, Australia, 2015; pp. 789-797. Available online: https://papers.acg.uwa.edu.au/p/150858-Farina (accessed on 10 July 2020).

48. Michelini, A.; Farina, P.; Coli, N.; Coppi, F.; Leoni, L.; Sá, G.; Costa, T. Advanced Data Processing of ground-based Synthetic Aperture Radar for slope monitoring in open pit mines. In Proceedings of the 48th US Rock Mechanics Geomechanics Symposium, Minneapolis, MN, USA, 1-4 June 2014; Available online: https://www.researchgate.net/publication/282699042 (accessed on 30 July 2020).

(C) 2020 by the authors. Licensee MDPI, Basel, Switzerland. This article is an open access article distributed under the terms and conditions of the Creative Commons Attribution (CC BY) license (http://creativecommons.org/licenses/by/4.0/). 